08

\title{
Структура углеродных дендритов, полученных в газовом разряде атмосферного давления
}

\author{
() М.П. Данилаев, ${ }^{1}$ Е.А. Богослов, ${ }^{1}$ Ю.Е. Польский, ${ }^{1}$ А.Р. Насыбуллин, ${ }^{1}$ М.С. Пудовкин, ${ }^{2}$ А.Р. Хадиев ${ }^{1,3}$ \\ ${ }^{1}$ Казанский национальный исследовательский технический университет им. А.Н. Туполева, \\ 420111 Казань, Россия \\ ${ }^{2}$ Казанский (Приволжский) федеральный университет, \\ 420008 Казань, Россия \\ ${ }^{3}$ ООО Центр трансорера и технологий, \\ 420107 Казань, Россия \\ e-mail: danilaev@mail.ru
}

(Поступило в Редакцию 22 марта 2016 г. В окончательной редакции 20 июня 2016 г.)

В работе исследовано влияние условий роста на структуру углеродных дендритов. Определены пороговые значения отношения температуры электронов $\left(T_{e}\right)$ к кинетической температуре газа вблизи игольчатого электрода $(T)$ и плотности разрядного тока, необходимые для роста углеродных дендритов. Показано, что гекасагональная структура субмикронных частиц углерода наблюдается при использовании различных исходных углеводородов для синтеза дендритов. Показано, что контролировать степень упорядочения углеродной структуры возможно внешними воздействиями на стадии формирования зародышей графеновых частиц. При этом характерные частоты инерциальных воздействий, которые могут оказаться целесообразными с энергетической точки зрения, должны быть более $10 \mathrm{kHz}$.

DOI: 10.21883/JTF.2017.02.44130.1816

В последние годы сильно возрос интерес к разработке технологий получения углеродных частиц различной аллотропической формы $[1,2]$. Это обусловлено высокой потребностью в таких частицах, например, в электронике, материаловедении, нефтехимии. При этом, как правило, требуется получение определенной аллотропической формы частиц с хорошей воспроизводимостью их структуры [3]. Один из перспективных методов получения углеродных частиц основан на использовании плазменных технологий $[4,5]$. Так, углеродные частицы различных аллотропических форм (например, чешуйчатые [6], вертикальные [7,8], дендритные [9]) получали в плазме газового разряда при атмосферном давлении. В общем случае в плазме газового разряда возможно образование двух типов углеродных частиц: сажа и пироуглерод [10]. В качестве исходных продуктов получения углеродных частиц возможно использование углеводородов, например мономеров в газообразном или жидком состоянии или продуктов пиролиза полимерных материалов [3]. В результате деструкции молекул углеводородов в объеме газового разряда образуются как отдельные атомы, так и группы атомов углерода, которые объединяются в полиароматические структуры с последующим образованием графеновых частиц. Характер упаковки графеновых частиц определяет будущую структуру углеродных частиц, например дендритов.

Сравнивая типовую структуру углеродных дендритов [4] и пироуглерода [11], возможно предположить, что механизмы их роста близки. Механизмы роста отличаются лишь тем, что для пироуглерода зародыши роста формируются на поверхности плоского электрода, а для дендритов - игольчатого электрода. Дендрит растет только в области разряда между электродами [4].
Причем в центральной части дендрита возможно формирование кристаллической углеродной структуры, которая переходит в аморфную по мере увеличения радиуса. Рост ветвей дендрита в поперечном сечении происходит в отдельных секторах, размеры которых определяются характерными размерами субмикронных углеродных частиц, образуемых в плазме из исходных продуктов синтеза. Совокупность этих ветвей образует структуры, напоминающие по форме „цветную капусту“ [4]. Порядок упаковки графеновых частиц в дендритах зависит от большого числа параметров (например, напряженность электрического поля в газовом разряде, давление, термодинамическая температура, исходные продукты синтеза). Однако в публикациях, например [6-9], посвященных получению углеродных частиц в плазме газового разряда, отсутствуют четко обоснованные результаты исследований влияния условий роста на порядок упаковки графеновых частиц в конгломератах. Это затрудняет выбор технологических параметров при серийном получении углеродных частиц с воспроизводимой структурой в плазме газового разряда.

Целью настоящей работы является выявление влияния условий роста на структуру как углеродных дендритов, так и составляющих их субмикронных углеродных частиц.

Исследование влияния условий роста на структуру дендритов проводилось на установке, схема которой представлена на рис. 1. Получение углеродных дендритов осуществлялось в плазме барьерного газового разряда атмосферного давления.

Буферный газ (аргон) из баллона 1 через вентиль 2 подавался в устройство формирования многофазного газового потока 3 , который через входной штуцер 5 


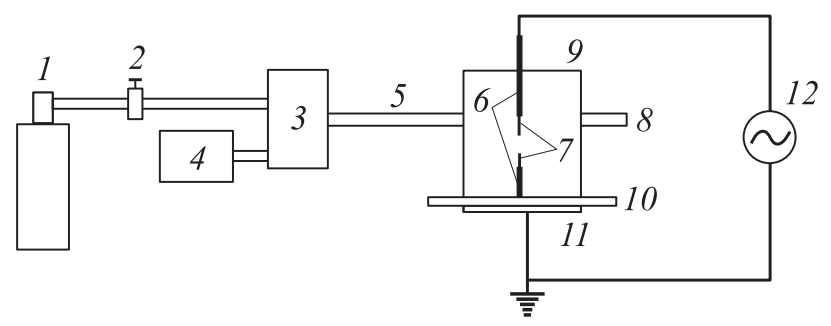

Рис. 1. Структурная схема экспериментальной установки: 1 баллон с буферным газом, 2 - вентиль, 3 - устройство формирования многофазного газового потока, 4 - источник углеводородов, 5 - входной штуцер, 6 - игольчатые электроды, 7 - углеродный дендрит, 8 - выходной штуцер, $9-$ разрядная камера, $10-$ диэлектрический барьер, $11-$ плоский электрод, 12 - высоковольтный источник.

поступал в плазмохимический реактор 9. В качестве источника углеводородов 4 использовалось устройство барботирования для жидких мономеров и пиролизная камера для полимерных материалов. Расход аргона в экспериментах составлял $200 \mathrm{ml} / \mathrm{min}$ и регулировался с погрешностью не более $10 \%$. Система электродов разрядной камеры имела конфигурацию „игла-игла“: стальные игольчатые электроды с радиусом закругления $0.5 \mathrm{~mm}$. Разряд зажигался через диэлектрический барьер 10, представляющий собой керамическое покрытие толщиной $1.5 \mathrm{~mm}$. Диаметр разрядной камеры 9 составлял $10 \mathrm{~cm}$. Плазма барьерного разряда формировалась источником переменного напряжения частотой $25 \mathrm{kHz}$. Напряжение на электродах барьерного газового разряда изменялось в пределах 5-25kV с погрешностью не более $10 \%$. В экспериментах обеспечивалось условие $\left(T_{e} / T\right) \sim 10$, где $T_{e}$ - температура электронов в плазме барьерного разряда, $T$ - термодинамическая температура вблизи игольчатого электрода [4]. При уменьшении отношения $T_{e} / T$ за счет уменьшения электронной температуры или увеличения температуры $T$ рост углеродных дендритов прекращался. Характерное значение температуры $T$ составляло $800-1200^{\circ} \mathrm{C}$ в зависимости от исходных продуктов синтеза и контролировалось пирометром с погрешностью измерений не более $5 \%$. Значение температуры $T_{e}$ принималось равным характерному значению температуры электронов для данного типа разряда [5]. Рост углеродных дендритов происходил с поверхности игл во встречном направлении до замыкания разрядного промежутка.

Первая серия экспериментов была направлена на выявление влияния исходных продуктов синтеза на структуру отдельных субмикронных частиц, составляющих дендрит. В качестве исходных продуктов синтеза дендритов использовались мономеры двух типов: мономеры, в структуре которых присутствует бензольное кольцо (бензол $\left(\mathrm{C}_{6} \mathrm{H}_{6}\right)$, стирол $\left(\mathrm{C}_{6} \mathrm{H}_{5} \mathrm{CH}=\mathrm{CH}_{2}\right)$ ), и мономеры, в структуре которых бензольного кольца нет (акрилонитрил $\left(\mathrm{CH}_{2}=\mathrm{CH}-\mathrm{CN}\right)$, метилметакрилат $\left(\mathrm{CH}_{2}=\mathrm{C}\left(\mathrm{CH}_{3}\right)-\right.$ $\left.\mathrm{COOCH}_{3}\right)$, пропилен $\left.\left(\mathrm{CH}_{2}=\mathrm{CH}-\mathrm{CH}_{3}\right)\right)$. Анализ структуры субмикронных частиц углерода, составляющих дендриты, проводился методами рентгеноструктурного анализа и электронной просвечивающей микроскопии.

Рентгеноструктурный анализ проводился для дендритов, полученных из различных исходных продуктов их синтеза, на рентгеновском дифрактометре RIGAKU SmartLab в режиме симметричной геометрии БрегаБрентано при следующих условиях: режим рентгеновской трубки - $45 \mathrm{kV}, 200 \mathrm{~mA}$, шаг сканирования $0.01^{\circ}$, скорость сканирования $-2 \circ \mathrm{min}$. На рис. 2 приведены типовые дифракторграммы для частиц, полученных из двух типов исходных мономеров, содержащих и не содержащих бензольное кольцо.

Следует отметить, что контролировать упорядоченность структуры субмикронных частиц, составляющих углеродные дендриты, возможно только на стадии формирования зародышей роста [10]. Для этого были проведены эксперименты по росту дендритов в аксиальном магнитном поле.

На дифрактограммах образцов (рис. 2) присутствует широкий дифракционный пик в области углов 20-25, представляющий собой суперпозицию двух пиков, положение максимумов которых соответствует межплоскостным расстояниям $d$, равным 0.44 и $0.35 \mathrm{~nm}$. Положение второго максимума, а также рефлекса (100) в области больших углов дифрактограммы (с соответствующим $d=0.21 \mathrm{~nm})$, соответствует гексагональному графиту
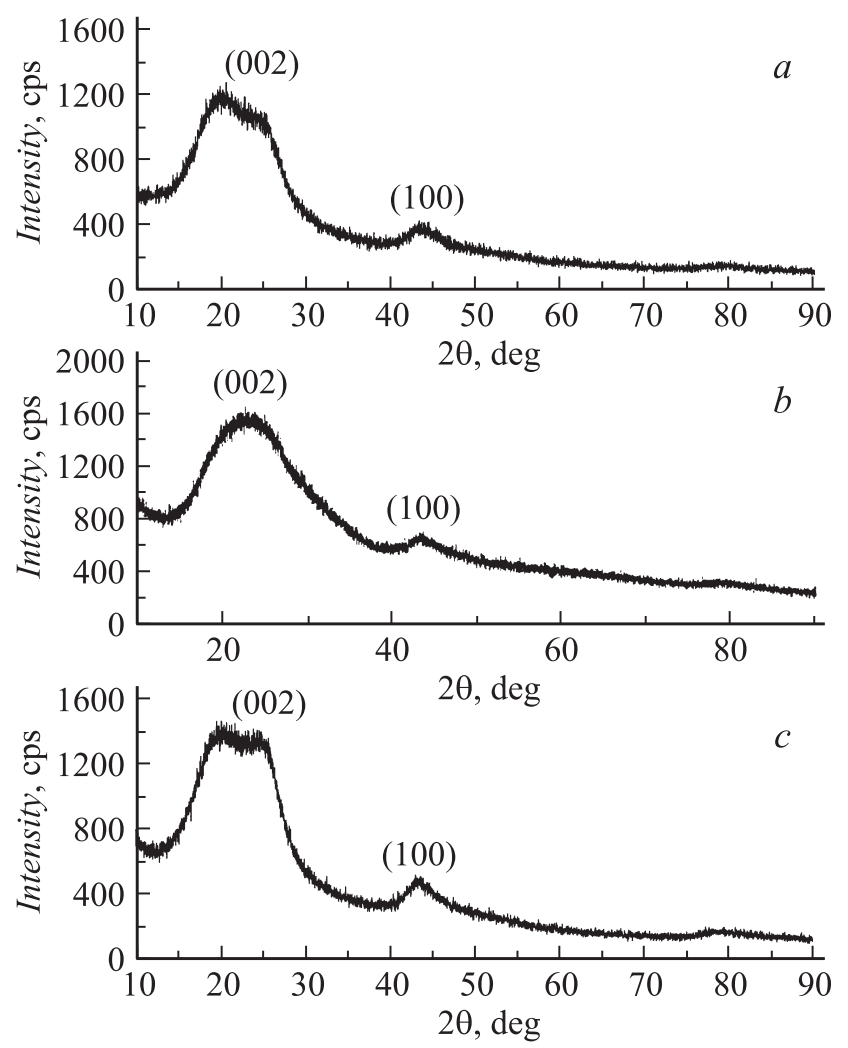

Рис. 2. Типовые дифрактограммы углеродных дендритов, где исходным продуктом синтеза является стирол $(a)$, акрилонитрил $(b)$, дифрактограмма для дендритов, полученных из стирола в аксиальном магнитном поле $(c)$. 

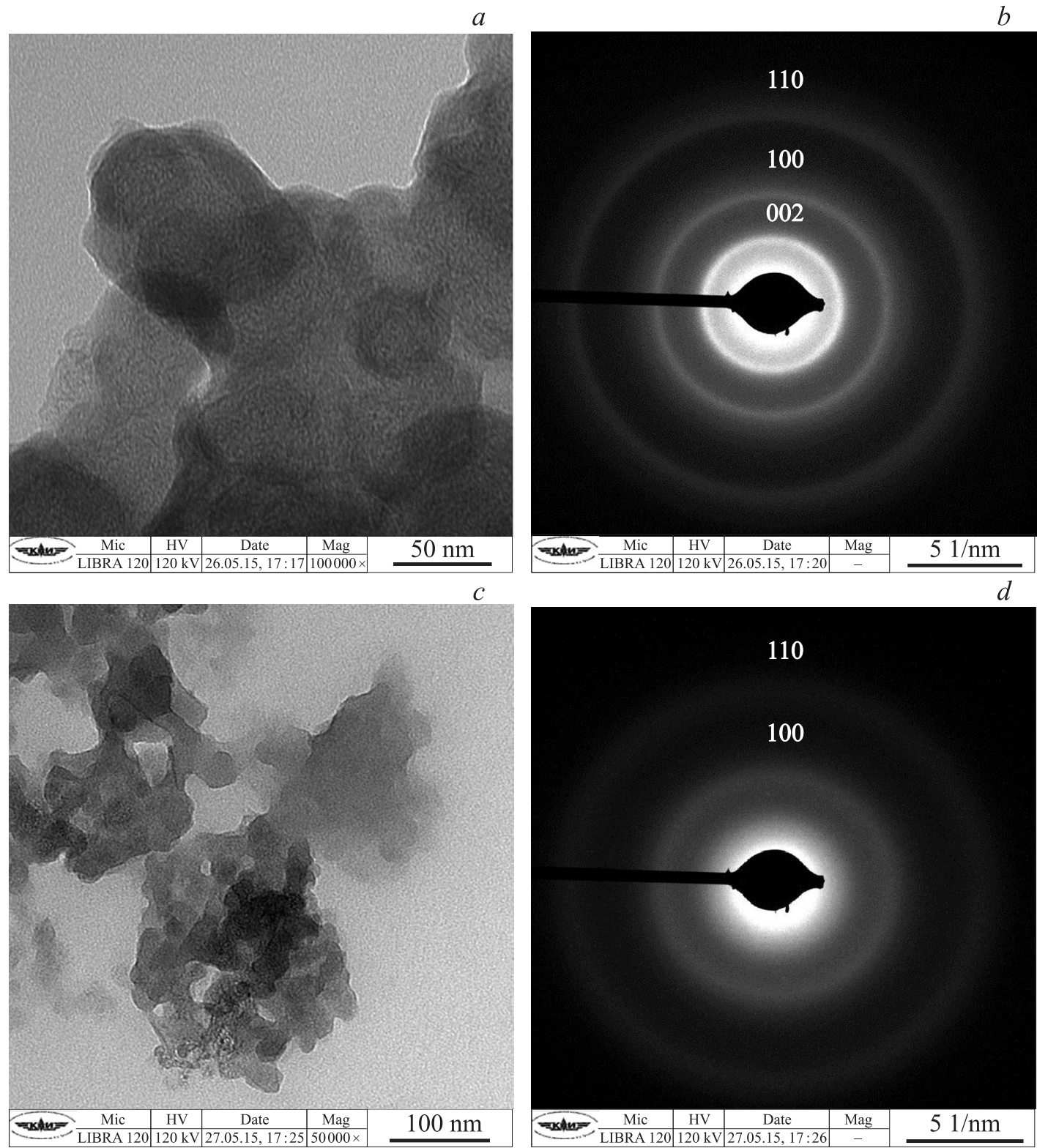

Рис. 3. Изображение просвечивающего электронного микроскопа частиц, полученных из стирола $(a)$, и их микродифракционная картина $(b)$; частиц, полученных из акрилонитрила $(c)$, и их микродиффракционная картина $(d)$.

(JCPDS 75-1621). Более четкая структура второго максимума (рис. 2,a,c) свидетельствует о большей доле упорядоченных углеродных структур в дендритах, полученных из исходных продуктов, содержащих бензольное кольцо. В типовой дифрактограмме, приведенной для образца, полученного из стирола в аксиальном магнитом поле (рис. 2,c), амплитуда второго максимума возросла по сравнению с амплитудой этого максимума на рис. 2, a. Это свидетельствует об увеличении доли упорядоченной структуры в углеродных дендритах.

Вопрос выбора вида и параметров квазиоптимальных воздействий, позволяющих обеспечить воспроизводимость требуемой структуры углеродных частиц, будет исследован отдельно. Однако отметим, что наиболее целесообразными с энергетической точки зрения могут оказаться инерциальные воздействия [12], характерные времена которых меныше характерных времен процессов образования зародышей. Поскольку характерное время формирования зародышей лежит в диапазоне от $\sim 10 \mathrm{~ns}$ до $\sim 0.1 \mu \mathrm{s}[10]$, то характерные времена инрециальных воздействий должны быть менее $0.1 \mu \mathrm{s}$.

Электронно-микроскопический анализ проводился на просвечивающем электронном микроскопе Zeiss Libra 120 со встроенным ОМЕГА фильтром при следующих условиях: ускоряющее напряжение - $120 \mathrm{kV}$, источник электронов - $\mathrm{LaB}_{6}$. Типовые микрофотографии и дифракционные картины электронных пучков представлены на рис. 3.

Дифракционные картины, полученные с различных областей углеродных дендритов, свидетельствуют о 


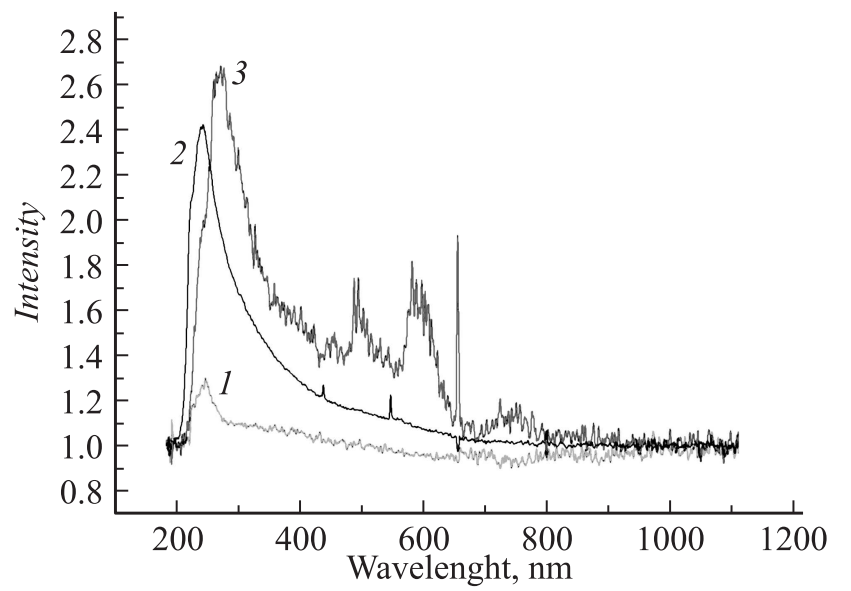

Рис. 4. Оптические спектры газового разряда при следующих исходных продуктах: 1 - стирол; 2 - метилметакрилат; 3 - пропилен.

том, что помимо частиц аморфного углерода с плохо выраженными дифракционными кольцами в образцах присутствует упорядоченная фаза углерода, которая имеет выраженные дифракционные максимумы. Межплоскостные расстояния $d_{002}=0.35 \mathrm{~nm}, d_{100}=0.21 \mathrm{~nm}$, $d_{110}=0.12 \mathrm{~nm}$ на дифракционной картине рис. $3, b$ соответствуют гексагональному графиту (JCPDS 75-1621). Это подтверждает формирование гексагональной углеродной структуры при различных исходных продуктах синтеза дендрита (исходных продуктах, содержащих и не содержащих бензольное кольцо).

Результаты микроскопических измерений хорошо согласуются с результатами рентгенодифракционного анализа рис. 2 и литературными данными [13]. Причем наличие дифракционного максимума 002 на картине дифракции электронов объясняет ассиметрию дифракционного пика 002 на рентгеновской дифрактограмме. Этот пик действительно состоит из двух пиков: от пика аморфного углерода $2 \theta \approx 24^{\circ}$ и пика от графитоподобной фазы углеродных сфер $2 \theta \approx 25.5^{\circ}$. Наличие пика 002 говорит об определенной степени порядка в укладке графеновых листов в наносферах вдоль кристаллографического направления (001). Характерные размеры углеродных наносфер лежат в диапазоне 40-100 nm. Следует отметить, что углеродные наносферы состоят из промежуточных фаз (графита и аморфного углерода) [14]. Поэтому выделение отдельно аморфных частиц и графитизированных углеродных наносфер довольно условно, особенно для участков дендрита, удаленных от его центральной части (в поперечном сечении). Ближе к центру упорядоченность графеновых слоев повышается, вплоть до образования кристаллической структуры углерода.

Исследование структуры отдельных углеродных частиц, образующихся в объеме газового разряда, осуществлялось методом оптической спектроскопии с использованием спектрометра StellarNet EPP2000 Spectrometer с разрешением $0.5 \mathrm{~nm}$. Типовые нормиро- ванные спектры представлены на рис. 4. Нормировка проводилась на спектры плазмы газового разряда в аргоне без содержания исходных продуктов синтеза дендритов.

Идентификация спектров проводилась с использованием результатов работ $[15,16]$. В спектрах наблюдаются линии поглощения в диапазоне длин волн 260-300 nm, характерные для частиц углерода гексагональной структуры. Эти линии появляются в спектре при превышении мощности разряда $200 \mathrm{~W}$, плотности тока разряда $25 \mathrm{~mA} / \mathrm{cm}^{2}$ и $T_{e} / T \sim 10$, что соответствует экспериментальным данным, полученным в работах $[4,16]$ при атмосферном давлении и [17] при давлениях $\sim 10^{2} \mathrm{~Pa}$. Увеличение приведенной амплитуды линий в диапазоне длин волн 260-300 nm, по всей видимости, связано с повышением интенсивности формирования в объеме частиц графена, что обусловлено увеличением плотности разрядного тока: образец $1-j_{0} \sim 25 \mathrm{~mA} / \mathrm{cm}^{2}$, образец $2-j_{0} \sim 35 \mathrm{~mA} / \mathrm{cm}^{2}$, образец $3-j_{0} \sim 45 \mathrm{~mA} / \mathrm{cm}^{2}$. Однако характерная скорость конденсации частиц графена на поверхности электродов для образцов 2 и 3 (рис. 4) меньше, чем для образца 1. Это связано с более высокими значениями температуры на поверхности игольчатых электродов при получении образцов 2 и 3.

Во второй серии экспериментов проводилось исследование структуры дендритов, полученных из различных углеводородов. Формирование углеродных дендритов начиналось с образования одного или нескольких каналов на острие игольчатого электрода. Увеличение напряженности поля приводило к росту числа ветвей и формированию кустообразных структур. Минимальная мощность разряда, необходимая для формирования углеродных дендритов, составила $\sim 200 \mathrm{~W}$. С увеличением подводимой мощности происходило увеличение скорости роста дендритов [4]. Увеличение подводимой мощности выше порога $\sim 300 \mathrm{~W}$ приводило к срыву роста дендритов из-за сильного разогрева игольчатого электрода. В пределах изменения напряженности поля в разряде $0.6-3 \mathrm{kV} / \mathrm{cm}$ средняя скорость роста составила для дендритов, полученных из стирола $\sim 1$, бензола $\sim 3.5$, пропилена $\sim 0.7$, метилметакрилата $\sim 0.5 \mathrm{~mm} / \mathrm{min}$ (погрешность измерений не более $10 \%$ ). Наибольшая скорость роста дендрита из бензола обусловлена отсутствием дополнительных реакций, необходимых для формирования гексагональной структуры углерода.

Анализ структуры дендритов проводился методом растровой электронной микроскопии на ожеэлектронном спектрометре JAMP-9510F („JEOL“, Япония). Условия проведения исследований - сверхвысокий вакуум (не хуже $\left.1 \cdot 10^{7} \mathrm{~Pa}\right)$, температура $+23^{\circ} \mathrm{C}$. Типовые микрофотографии и оже-спектры представлены на рис. 5 для дендритов, полученных из пропилена.

В оже-спектрах (рис. 5, c), полученных из центральной области дендрита, присутствует аргон. Следует отметить, что амплитуда соответствующего пика не изменялась после выдержки образца при давлениях $10^{-9} \mathrm{~Pa}$ в течении трех суток. Это свидетельствует о кристал- 

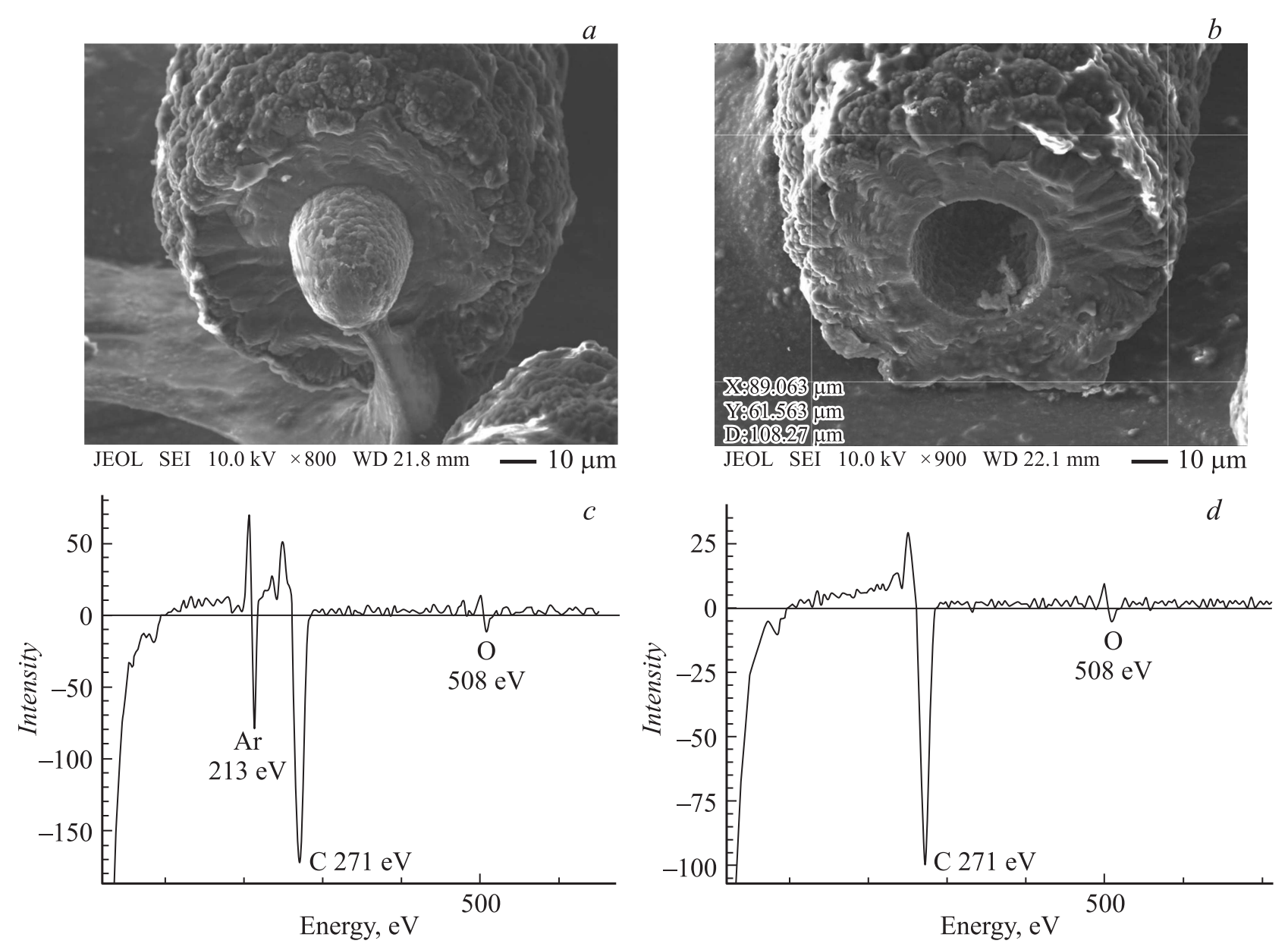

Рис. 5. Типовые микрофотографии и соответствующие им оже-спектры.

лической структуре углерода в центре дендрита, состоящей из упорядоченных слоев графена, которые, как известно, не проницаемы для атомов газа [10]. По мере удаления от центра дендрита растет доля аморфного углерода, который уже не способен удерживать атомы аргона. Присутствие аргона в центральной части дендрита может быть обусловлено тем, что образующиеся молекулы эксимера $\mathrm{ArC}$ являются зародышами роста частиц графена. Следует отметить, что наличие аргона в центральной части дендритов наблюдалось только в случае их формирования из пропилена. Это связано с более высокой плотностью тока разряда, чем при формировании дендритов из стирола, акрилонитрила $\left(j_{0} \sim 28 \mathrm{~mA} / \mathrm{cm}^{2}\right)$, метилметакрилата.

Таким образом, проведенные экспериментальные исследования показывают, что необходимыми условиями формирования углеродных дендритов в плазме барьерного разряда атмосферного давления являются:

1) отношение температуры электронов $\left(T_{e}\right)$ к кинетической температуре газа вблизи игольчатого электрода $\left(T_{e} / T\right) \sim 10$

2) плотность разрядного тока $j_{0}$ не менее $25 \mathrm{~mA} / \mathrm{cm}^{2}$.

Показано, что при выполнении этих условий структура дендрита меняется от кристаллической в центре до аморфной по мере увеличении радиуса. Это обусловлено распределением плотности разрядного тока. Причем контролировать степень упорядочения углеродной структуры возможно внешними воздействиями на стадии формирования зародышей графеновых частиц. При этом характерные частоты инерциальных воздействий, которые могут оказаться целесообразными с энергетической точки зрения, должны быть более $10 \mathrm{kHz}$.

Минимальным фракталом в субмикронных углеродных частицах является шестиугольник, в вершинах которого расположены атомы углерода. Причем гексагональная структура субмикронных частиц углерода наблюдается при различных условиях получения дендритов: мощность разряда 200-300 W, напряженность поля в разряде $5-25 \mathrm{kV}$, различные типы исходных углеводородов для синтеза дендритов.

Авторы благодарят доктора технических наук И.А. Косско и кандидата технических наук А.Е. Денисова за участие в экспериментальных исследованиях и обсуждение результатов.

Работа выполнена при поддержке задания № 11.34.214/К на выполнение государственных работ в сфере научной деятельности. 


\section{Список литературы}

[1] Кольцова Т.С., Ларионова Т.В., Шушарина Н.Н., Толочко О.В. // ЖТФ. 2015. Т. 85. Вып. 8. С. 110-115.

[2] Михайлин Ю.А. Конструкционные полимерные композиционные материалы. СПб.: НОТ, 2013. 822 с.

[3] Лепешев А.А, Ушаков А.В., Карпов И.В. Плазмохимический синтез нанодисперсных порошков и полимерных нанокомпозитов. Красноярск: Изд-во Сиб. федер. ун-та, 2012. $328 \mathrm{c}$.

[4] Данилаев М.П., Богослов Е.А., Польский Ю.Е. // Письма в ЖТФ. 2014. Т. 40. Вып. 19. С. 60-66.

[5] Ясуда Х. Полимеризация в плазме / Пер. с англ. М.: Мир, $1988.376 \mathrm{c}$.

[6] Hunga Nsung-Chi, Chenb Chua-Fu, Chenc Chien-Chung, Whang Wha-Tzong. // Appl. Surf. Sci. 2009. Vol. 255. P. 3676-3681.

[7] Bo Zheng, Kehan Yu, Ganhua Lu, Shumao Cui, Mao Shun, Junhong Chen. // Energ. Envir. Sci. 2011. Vol. 4. P. 25252528.

[8] Bo Zheng, Kehan Yu, Ganhua Lu, Wang Pengxiang, Mao Shun, Junhong Chen. // Carbon. 2011. Vol. 49. P. 1849 1858.

[9] Dmytro Kozak, Etsuro Shibata, Atsushi Iizuka, Takashi Nakamura // Carbon. 2014. Vol. 70. P. 87-94.

[10] Щур Д.В., Матысина З.А., Загинайченко С.Ю. Углеродные наноматериалы и фазовые превращения в них. Монография. Днепропетровск: Наука и образование, 2007. $680 \mathrm{c}$.

[11] Синани И.Л., Бушуев В.М. // Коррозия, материалы, защита. 2012. № 2. C. 28-32.

[12] Афанасьев В.В., Польский Ю.Е. // ЖТФ. 1992. Т. 62. Вып. 12. C. 28-33.

[13] Deshmukh A.A., Mhlanga S.D., Coville N.J. // Mat. Sci. Eng. R. 2010. Vol. 70. P. 1-28.

[14] Kang J., Li O.L., Saito N. // Carbon. 2013. Vol. 60. P. 292298.

[15] Шелестова В.А., Жандаров С.Ф., Данченко С.Г., Гракович П.Н. // Физика и химия обработки материалов. 2014. № 4. C. $12-19$.

[16] Liberman M.A., Lichtenberg A.J. Principles of plasma discharges and materials processing. New Jersey: Published by John Wiley \& Sons, Inc., Hoboken, 2005.

[17] Gillon X., Li Z., Diallo M., Houssiau L., Pireaux J-J. Plasma polymerization: Correlation between internal plasma parameters and film characteristics. Intern. Symp. of Plasma Chemistry. ISPC19-2009. Bochum, Germany. 